\title{
Antifeedant Activity of Leaf Aqueous Extracts of Selected Medicinal Plants on VI Instar Larva of Helicoverpa Armigera (Hubner)
}

\author{
${ }^{1}$ G.Ravi, ${ }^{2}$ G.Sundararajan ${ }^{*}$ \\ Asst. professor in Botany, Govt.Arts College, Dharmapuri-5, Tamil nadu, India
}

\begin{abstract}
Phytochemicals, especially botanical insecticides are currently of interest because of their successful application in plant protection as bio control agents. Biological activity of leaf aqueous extract of ten selected medicinal plants were evaluated against the fourth-instar larvae of gram pod borer Helicoverpa armigera (H“ubner), (Lepidoptera: Noctuidae). Antifeedant activity of leaf aqueous extracts of Abutilon indicum L., Achyranthus aspera L., Aerva lanata L., Albiziz amara (Roxb), Andrographis paniculata Ness., Cardiospermum halicacabum L., Cassia tora L., Catharanthus roseus L (G) Don., Datura metal L. and Tribulus terrestris L. were evaluated in this study. Preliminary screening after $24 \mathrm{~h}$ of exposure with leaf aqueous extracts of the selected plants at a concentration of $1,000 \mathrm{ppm}$ exhibited significant larval mortality rate. The percentage mortality rate ranged considerably from 10.8 to 72.8 . The mortality rate was observed in the decreasing order of A. paniculata $>$ C. roseus $>$ D. metal $>$ A. amara $>$ C. halicacabum $>$ A. indicum $>$ C. tora $>$ T. terrestris $>$ A. aspera $>$ A. lanata against the larvae of $\mathrm{H}$. armigera. The results imply that leaf aqueous extract of A. paniculata, C. roseus and D. metal can potentially be used as ecofriendly pest control agents against the larva of $\mathrm{H}$. armigera.
\end{abstract}

Keywords: Antifeedant activity, Leaf aqueous extracts, H.armigera

\section{Introduction}

India is basically an agro-based country more than $80 \%$ of Indian population depends on agriculture. Indian economy is largely determined by agricultural productivity. Insect-pests are known to cause significant damage to crops and affect agricultural productivity. The monetary loss due to feeding by larvae and adult insects alone contributes to billion dollars per annum (Jacobson, 1982). Among the Lepidopteran, Pod borer - Helicoverpa armigera is the key pest that cause severe damage to crop plants and bring about significant yield loss. Helicoverpa armigera, commonly known as cotton bollworm or American bollworm, is a major polyphagous noctuid pest in Asia, causing heavy damage to agricultural, horticultural and ornamental crops (Talekar et al., 2016). H. armigera infests several plants like cereals, pulses, cotton, and vegetable besides it has been reported to attack wild hosts. In central and north India, it is the major pest affecting cotton. The larvae feed extensively on cotton plant parts including the newly emerging bolls causing severe loss of crop. Bollworms are relatively safe from natural enemies because of the cryptic feeding habits of the larvae within cotton bolls. Therefore, large numbers of $H$. armigera in cotton and other vegetables survive to adults that may disperse widely, producing progeny that damage high-value crops (Cabanillas and Raulston 1995; Michael and Donald 1996). Economic loss due to this pest in India accounts for 5,000 cores (Manjunath et al., 2015). Helicoverpa armigera has a long history of resistance to conventional insecticides. Variety of chemical insecticides and pesticides are used to control $H$. armigera. However, harmful effects and persistent nature of the chemical pesticides demand for eco-friendly alternatives. During the last 50 years, worldwide use of synthetic insecticides to control insect pests has led to both insecticide resistance and environmental persistence (Roush, 1990). Plant derived phytochemicals have been widely used in the management of agricultural pest since time immemorial (Choudary, 2001). Plant derived pesticides are ecofriendly, non-toxic to non-target organisms, non persistent in nature, besides they do not promote drug resistance (Liu et al., 2000). 
Therefore, researchers world over are engaged in a mission to hunt for novel phytochemicals that could potentially be used in the management of insect-pests. Plants are endowed with a potential to produce a range of secondary metabolites like alkaloids, terpenoids, flavonoids, phenols, glycosides, sitosterols and tannins. These phytochemicals are known to protect the plants from the attack of insect-pests (Ahmad, 2007). However, production of phytochemicals varies from plant to plant. Further, parameters like age of plant, part of plant (root, stem, leaf, fruit, flower, seed and bark) have been reported to affect the production of phytochemicals. The phytochemicals produced in response to insect-pest attack, affect feeding and oviposition of insects on the plants.

Application of bio-pesticides has been reported to have positive impacts on bollworm population management (Ge and Ding 1996). A number of plants have been shown to have pesticidal and antifeedant activity against $H$. armigera of which Neem has been subjected to extensive investigation by Chopra $e t$ al., (1994). Studies have shown that Acorus calamus, Annona squamosa, Vitex negundo are effective in the management of $H$. armigera (Murugan et al., 2017). Sundararajan and Kumuthakalavalli, (2019) evaluated antifeedant activity of aqueous extract of Gnidia glauca and Toddalia asiatica against $H$. armigera. In this view, effect of leaf aqueous extracts of selected medicinal plants viz., A. indicum, A. aspera, A. lanata, A. amara, A. paniculata, C. halicacabum, C. tora, C. roseus, D. metal and T. terrestris have been evaluated for their efficacy in the management of the insect pest $H$. armigera.

\section{Materials and Methods}

\section{Preparation of extract}

Selection of plants used in the present study was made on the basis of their availability and absence of damage by the insect-pest. Healthy plant materials were collected from the wild in poly bags and brought to lab and their botanical identity was established. Fresh leaves from the selected plants were collected and washed separately. About $1 \mathrm{gm}$ of fresh leaf material was ground with distilled water using mortar and pestle. The extract was filtered and the filtrate was made upto $100 \mathrm{ml}$ and was maintained as stock. The leaf aqueous extract was diluted with distilled water to obtain $1 \%$ test solution used in the bioassay studies.

\section{Test organism}

The larvae used for the study were collected from the host plants in the cotton fields and brought to lab. They were reared on artificial diet under laboratory conditions. Studies were carried out using VI instar larvae of $H$. armigera against the aqueous extract of all the selected plant species. The percentage mortality was calculated after a period of $24 \mathrm{~h}$ by using bioassay studies.

\section{Bioassay studies}

Studies were conducted for a period of $24 \mathrm{~h}$ in the laboratory in transparent plastic containers of $4 \times 2.5 \mathrm{~cm}$ size capped with perforated plastic lids. Fresh leaves of Lycopersicum esculentum (tomato) were collected from the field and washed in water. Excess moisture was removed from the leaves and the leaves were dipped in $1 \%$ test solution, shade dried and served to the VI instar larvae of $H$. armigera. Extract free leaves served as control. For each treatment 10 larvae were singly introduced in separate containers after six hour starvation. Three replicates each of ten larvae were maintained for each treatment. All the experiments were conducted at $27^{\circ} \pm 1,75 \%$ humidity and $14 \mathrm{~h}$ dark period. Twenty four hour larval mortality was observed and the percentage mortalities were corrected using Abbott's formula (Abbott, 1925).

\section{Results}

The aqueous extracts of selected plant species collected from Dharmapuri Districts of Tamil Nadu were subjected to bioassay studies against the VI instar larva of $H$. armigera (24h) and the percentage mortality rate was observed. The results are given in Table 1. 
Table 1: Effect of leaf aqueous solutions on the larvae of H. armigera

\begin{tabular}{|l|l|l|l|}
\hline S. No & Botanical name & Family & Mortality Rate (\%) \\
\hline 1. & Aerva lanata L. & Amaranthaceae & $\mathbf{1 0 . 8}$ \\
\hline 2. & Achyranthus aspera L. & Amaranthaceae & $\mathbf{1 6 . 8}$ \\
\hline 3. & Tribulus terrestris L. & Zygophylaceae & $\mathbf{2 5 . 2}$ \\
\hline 4. & Cassia tora L & Caesalpiniaceae & $\mathbf{3 1 . 8}$ \\
\hline 5. & Abutilon indicum L. & Malvaceae & $\mathbf{3 5 . 2}$ \\
\hline 6. & Cardiospermum halicacabum L & Sapindaceae & $\mathbf{4 2 . 8}$ \\
\hline 7. & Albiziz amara (Roxb). & Minosaceae & $\mathbf{5 1 . 8}$ \\
\hline 8 & Datura metal L. & Solanaceae & $\mathbf{6 2 . 2}$ \\
\hline 9. & Catharanthus roseus L (G) Don. & Apocanaceae & $\mathbf{6 7 . 8}$ \\
\hline 10. & Andrographis paniculata Ness. & Acanthaceae & $\mathbf{7 2 . 8}$ \\
\hline
\end{tabular}

It was observed that all the selected plant species exhibited antifeedant activity against the larvae of $H$. armigera. However, the percentage mortality rate varied significantly among the plants tested. The percentage mortality rate of the insects ranged from 10.8 to 72.8. The mortality rate was observed in the decreasing order of $A$. paniculata $>C$. roseus $>D$. metal $>A$. amara $>C$. halicacabum $>A$. indicum $>C$. tora $>$ T. terrestris $>A$. aspera $>A$. lanata against the larvae of $H$. armigera. The leaf aqueous extracts of three plants namely A. paniculata, C. roseus and D. metal exhibited high rate of mortality $(72.8,67.8$ and 62.2 percent respectively) against the larvae of $H$. armigera.

\section{Discussion}

Prohibitive expense to meet the challenges of increasing resistance in insects, resurgence of pests and escalating environmental pollution caused by synthetic pesticides call for the discovery of less-expensive, non-hazardous alternatives in the management of insect-pests. Plants are endowed with a potential to produce a wide

Spectrum of allelo-chemicals (Norduland and Sauls, 1981). Insects have been influential in the evolution of allelochemicals in plants which in turn affects the insects. Some of compounds affect the feeding behavior of the insects and inhibit feeding, while few others disrupt hormonal balance there by inhibits growth, metamorphosis and reproduction. Due to aforesaid reasons there is resurgence of interest in plant derived compounds for developing them novel eco-friendly insecticides on commercial scale (Jacobson and Crosby, 1971). Despite hundreds of plants have insecticidal property, only few compounds like Azadirachtin (known to disrupt the action of moulting hormone) and pyrethroids (brings about paralysis of the insects) have been commercialized. However, an understanding of structure-activity relationship and knowledge on the mode of action is required for large-scale production. For successful exploitation of a bio-insecticide, screening of phytochemicals for wide spectrum of behavioral and physiological activities in poly-phagous insects is essential. Koul et al., (2000) administered phytochemical extracts orally through food to determine the toxicity or efficacy of plant materials for antifeedancy, inhibition of growth or emergence as adults. Murugan et al (2017),

Followed no-choice method in which the test insect was provided with treated leaf disc. Dual choice method mimics the situation in the field, and is valuable in assessing the antifeedancy of phytochemicals. However, this method does not facilitate administration of apt quantity of plant extract to the insects. On the other hand, no-choice bioassay method provides on opportunity to precisely administer the desired quantity of extract to the insect. Hence in the present study, no-choice bioassay method was followed for assessing the insecticidal activity of the different plant extracts. Usually larger doses of plant extracts inflict mortality either by inhibiting feeding or reducing digestibility or inhibiting growth. Smaller doses of extracts may not be adequate for killing the insects however it may sometimes induce malformation (Ahmad, 2007). Induction of morphogenetic deformities during larval development or metamorphosis has greater impact on 
population build up. Malformed adults are unable to participate in reproductive activities and hence do not help building up the population. High antifeedancy (low ED50) has been reported for

Pure compounds isolated from different plants by Simmonds et al., (1990). Aqueous extracts of Calotropis procera and Datura stromonium display about $90 \%$ feeding protection against $H$. armigera (Dodia et al., 1998). Likewise, it has been reported that the effectiveness of the phytochemicals depend on the extraction method used. Janarthan et al., (1999) reported that petroleum ether extracts of Parthenium histerophorus at a concentration of 0.2 and $0.5 \%$ cause $100 \%$ mortality in the larvae of $\mathrm{H}$. armigera. Antifeedant property of plant extracts brings about retardation of growth and ultimately results in death of the insect. However, compounds which do not display antifeedant property are reported to have growth regulatory activity (Kraus et al., 1987). On the other hand, a few plant extracts display bimodal activity. At high concentrations they are as feeding deterrents and at low concentrations as growth inhibitors (Nawrot et al., 1991). Jermy (1990) reported that extracts with antifeedant and toxic effect are more successful in practical application as they evoke behavioral effect of antifeedancy. Jaglan et al (1997) evaluated the effect of Azadirachta indica extracts against $H$. armigera and reported that Chloroform: methanol (9:1) extracts of Neem seed kernels and leaves showed better insecticidal properties than methanol extracts. On the other hand Koul et al., (2000) reported that $H$. armigera larva fed on azadirachtin treated leaf suffered dose dependant effect on growth. Young larvae fed on $4 \mathrm{ppm}$ azadirachtin treated leaf initially gained weight however, older larvae fed on 4 ppm azadirachtin leaf suffered $75 \%$ decrease in growth compared with the control larva (Koul, 1985). Similar observations were made by Murugan and Babu (2017) on growth and feeding physiology of H. armigera larva on extracts of Ricinus communis, Glycosmis pentaphylla, Vitex negundo and Nerium

Oleander. Murugan et al., (2017) reported that larvae fed on $0.3 \%$ ethylaceteate fraction of Glycosmis pentaphylla, Vitex negundo and Nerium oleander showed significant effect on initial weight $(259,181$ and $177 \%$ ) in $48 \mathrm{~h}$ compared to weight gained by the control larva $(898,972$ and $890 \%)$. However, earlier it has been reported that the aqueous leaf extracts of Gnidia glauca showed more than $50 \%$ larval mortality at 0.8 $1.0 \%$ and $86.1 \%$ mortality observed at $1.0 \%$ on Toddalia asiatica extract against the sixth-instar larvae of $H$. armigera (Sundararajan and Kumuthakalavalli, 2019). In the present study all the tested plant extracts exhibited antifeedant activity on $H$. armigera. Of the 10 species of the plants screened for insecticidal property, three plant species (A. paniculata, C. roseus and D. metal) showed high rate of mortality, i.e. above $60 \%$, on application of aqueous extracts against the VI instar larva of $H$. armigera.

\section{Conclusion}

In conclusion, the study reveals that leaf aqueous extracts of A. paniculata, C. roseus and D. metal can potentially be used as eco-friendly bio-pesticide to control the devastating damage caused by VI instar larva of $H$. armigera. However, harmful effects and persistent nature of the chemical pesticides demand for ecofriendly alternatives. During the last 50 years, worldwide use of synthetic insecticides to control insect pests has led to both insecticide resistance and environmental persistence. Plant derived phytochemicals have been widely used in the management of agricultural pest since time immemorial. Plant derived pesticides are eco-friendly, non-toxic to non target organisms, non persistent in nature, besides they do not promote drug resistance.

This research did not receive any specific grant from funding agencies in the public, commercial, or not for profit sectors.

\section{References}

[1.] Abbott WS (1925) A method for computing the effectiveness of an insecticide $J$ Econ Ent 18:265267.

[2.] Ahmad Mahmood (2007) Insecticide resistance mechanisms and their Management in Helicoverpa armigera (Hübner) - A review J Agric Res 45(4): 319-335.

[3.] Cabanillas HE, Raulston JR (1995) Impact of Steinernema riobravis (Rhabditida: Steinernematidae) on the control ofHelicoverpa zea (Lepidoptera: Noctuidae) in corn $J$ Econ Entomol 88:58-64.

[4.] Chopra RN, Badhwar R and Ghosh S (1994) Poisonous Plants of India ICAR New Delhi, India.

[5.] Choudhary RK, Veda OP and Mandloi KC (2001) Use of Neem, Azadirechta indica and garlic, Allium sativum in the management of bolloworms, Helicoverpa armigera in cotton In: Proc 88th Session of the Indian Sci Cong Agric Sci, New Delhi. 40-42. 
[6.] Dodia DA, Patel IS and Pathak AR (1995) Antifeedant properties of some indigenous plant extracts against larvae of Helicoverpa armigera Pestol 19:21-22.

[7.] Ge F and Ding Y (1996) The population energy dynamics of predacious natural enemies and their pest control activity in different cotton agroecosystems. Acta Entomol Sin 39:266-273.

[8.] Jacobson (1982) The potential role of natural product chemistry research in Heliothis management. In: Proc. Internt. Patacheru, Andrapradesh, India 233-240.

[9.] Jacobson M and Crosby DG (1971). Naturally occurring insecticide (Eds Marcel and Dekker) 212219.

[10.] Jaglan MS, Khokhar KS, Malik MS and Singh R (1997) Evaluation of Neem (Azadirachta indica A. Juss) extracts against American bollworm, Helicoverpa armigera (Hubner) J Agri Food Chem 45:3262-3268.

[11.] Janardhan RS, Chitra KC, Kameswara RP and Subramaniyam RK (1999) Antifeedant and insecticidal properties of certain plant extracts against Helicoverpa armigera J Insect Sci, 5:163164.

[12.] Jermy T (1990) Prospects of antifeedant approach to pest control - a critical review J Chem Ecol, 16:3151-3166.

[13.] Koul O (1985) Azadirachtin interaction with development of Helicoverpa armigera Fab Indian J Expt Biol 23:160-163.

[14.] Koul O, Jain MP and Sharma VK (2000) Growth inhibitory and antifeedant activity of extracts from Melia dubia to Spodoptera litura and Helicoverpa armigera larvae. Indian J Exp Biol 38(1):63-68.

[15.] Kraus W, Baumann S, Bokel M, Keller U, Klenk A, Klingele M, Pohnl H and Schwinger M (1987) Control of insect feeding and development by constituents of Melia azadirach and Azadirachta indica Proc $3^{\text {rd }}$ International Neem Conference, Nairobi, Kenya, 375 - 385.

[16.] Liu SQ, Shi JJ, Cao H, Jia FB, Liu XQ, Shi GL (2000) Survey of pesticidal component in plant In: Entomology in

[17.] China in 21st Century, Proceedings of Conference of Chinese Entomological Society (Ed: Dianmo) Li Beijing, China: Science \& Technique Press. 1098-1104.

[18.] Manjunath TM, Bhattnagar VS, Pawer CS and Sidhanantham S (2015) Economic importance of Heliothis armigera (Hubner) in India an assessment of their natural enemies and host plants In: Proc. Workshop on Biological control of Heliothis armigera ND, India.

[19.] Michael AF and Donald CS (1996) Inundative biological control of Helicoverpa zea (Lepidoptera: Noctuidae) with the entomopathogenic nematode Steinernema riobravis (Rhabditida: Steinernematidae) Biol Control 7:38-43.

[20.] Murugan K and Babu R (2017) Impact of certain plant products and Bacillus thurengiensis Berliner sub sp. Kurstaki on the growth and feeding physiology of Helicoverpa armigera (Hubner) JSIR 57:757-765.

[21.] Murugan K, Sivaramakrishnan S, Senthilkumar N, Jayabalan D and Senthil Nathan S (2017) Syneristic interaction of botanicals and Biocides Nuclear polyhedrosis virus on pest control JSIR 57:732-739.

[22.] Nawrot J, Koul O, Isman MB and Harmatha J (1991) Naturally occurring antifeedants: effects on two polyphagous lepidopterans J Appl Entomol 111:194-201.

[23.] Norduland DA and Sauls GE (1981) Kairomones and their use for the management of entomophagous insects J Gen Ecol 7:1057-1061.

[24.] Roush R T and BE Tabashnik (1990) Pesticide resistance in arthropods. Chapman and Hall, New York, NY.

[25.] Simmonds MSJ, Blaney WM and Fellows FE (1990) Behavioral and electro-physiological study of antifeedant mechanisms associated with polyhydroxy alkaloids. J Chem Ecol 16:3167-3196.

[26.] Sundararajan G and Kumuthakalavalli R (2019) Antifeedant activity of aqueous extract of Gnidia glauca Gilg. And Toddalia asiatica Lam. on the gram pod borer, Helicoverpa armigera (Hbn). $J$ Environ Biol 22(1):11-14.

[27.] Talekar NS, Opeña RT and Hanson P (2016) Helicoverpa armigera management: a review of AVRDC's research on host plant resistance in tomato Crop Protect 5:461-467. 